\title{
Preventive Effect of Albumin Nano TPA Gene Plasmid Ultrasound Microbubble Carrier System on Thrombosis after Cardiac Valve Replacement
}

\author{
Feng Qi, ${ }^{1}$ Linlin Zhao, ${ }^{2}$ Guohua Cai, ${ }^{1}$ Zhendong Sun, ${ }^{1}$ and Naishi Wu ${ }^{1}$ \\ ${ }^{1}$ Department of Cardiac Surgery, Second Affiliated Hospital of Harbin Medical University, Harbin 150086, China \\ ${ }^{2}$ Department of Cardiac Surgery, Liaoning Provincial People's Hospital, Shenyang 110016, China \\ Correspondence should be addressed to Naishi Wu; wnsh68@126.com
}

Received 25 July 2020; Revised 6 October 2020; Accepted 5 November 2020; Published 21 November 2020

Academic Editor: Tifeng Jiao

Copyright (C) 2020 Feng Qi et al. This is an open access article distributed under the Creative Commons Attribution License, which permits unrestricted use, distribution, and reproduction in any medium, provided the original work is properly cited.

\begin{abstract}
After cardiac valve replacement, most patients will have different degrees of thrombosis, different parts of the thrombus, and even more frequent occurrence of postoperative thrombosis; therefore, the prevention of postoperative thrombosis is particularly important. The purpose of this study was to investigate the preventive effect of albumin nano tPA gene plasmid ultrasound microbubble carrier system on thrombosis, especially in cardiac valve. The experimental control method was used. Firstly, 11 dogs meeting the experimental requirements were selected. Secondly, the data of albumin nanoparticles and microbubbles were analyzed. The average size of albumin particles was $132.0 \mathrm{~nm}$, the average size of microbubbles was $3.1 \pm 1.6 \mu \mathrm{m}$, and the zeta potential was $13.70 \pm 1.95 \mathrm{MV}$. The concentration of microbubbles was $4.2 \pm 1.3 \times 10 / \mathrm{ml}$. Finally, 11 dogs were divided into two groups. The experimental group was treated with albumin nanoparticles ultrasound microbubble, and the others were the control group. It was found that the levels of $\mathrm{PPA}$ and $\mathrm{D}$-dimer in the experimental group were significantly increased and maintained at a high level at 1 week after operation, and the prothrombin time was detected and the international normalized ratio was calculated at the same time. No significant changes were found in the experimental group.
\end{abstract}

\section{Introduction}

Valvularheart disease is a kind of serious heart disease, which could lead to heartfailure, dyspnea, and edema; valve replacement should be carried out in time. Congenital heart valve disease has life-threatening consequences, which requires early valve replacement. In addition, after cardiac valve replacement, hemorheology changes abnormally and produces emboli, which leads to the possibility of cerebral embolism, reaching 50\%. Albumin nanoparticles were initially used only as diagnostic reagents. Now, albumin nanoparticles are a relatively mature drug delivery system, and related drugs and diagnostic agents have been put on the market $[1,2]$. Albumin nanoparticles can be administered through a variety of ways, such as intravenous injection, intramuscular injection, oral administration, and intra-arterial injection [3,4]. Tissue-type plasminogen activator
(tPA) is a tissue plasminogen activator that selectively activates plasmin $[5,6]$. However, the way in which plasmatype activator gene can be effectively transferred into terminal cells has not been solved. Therefore, whether the plasma tissue-type activator can be effectively expressed for a long time and play a local anticoagulant effect is still a key problem to be solved $[7,8]$. Oschatz pointed out in the study that clinical transcatheter heart valve thrombosis is more common than previously thought, which is characterized by imaging abnormalities, gradient increase, and N-terminal pro brain natriuretic peptide level, which mostly occurs after balloon dilated transcatheter aortic valve replacement and valve replacement $[9,10]$. To test this idea, he studied 87 patients [11, 12]. Among the 87 patients, $46(53 \%)$ had mitral valve replacement, 27 (31\%) had aortic valve replacement, and $14(16 \%)$ had double valve replacement. The research of Oschatz is accidental and its reliability is not high $[13,14]$. In 
order to explain the influence of element measurement on bubble size distribution, Sauter's average diameter, and volume mass transfer coefficient as performance indicators of pressure dissolved microbubble generator, Dasi studied the influence of swirl chamber, crushing plate, and other elements on the performance of pressurized dissolved microbubble generator $[15,16]$. In the process of the experiment, Dasi used a crushing disk and B-type cyclone chamber to improve the efficiency of the pressurized dissolved microbubble generator. At the same time, the experimental results were quantitatively summarized $[17,18]$. Dasi's research results show that in terms of influencing bubble size, the crushing disk has the best efficiency, and its contribution rate to D50 and Sauter's average diameter is $27.84 \%$ and $45.16 \%$, respectively. In other cases, the influence of swirl chamber on mass transfer coefficient is better than that in other cases $[19,20]$. Dasi's research has great reference value, but the economy of its research method needs to be improved [21, 22]. In order to prepare ultrasound microbubbles carrying herpes simplex virus thymidine kinase (HSV-TK) gene and target HepG2 cells, Carlyle observed its targeting ability in vitro and its inhibitory effect on proliferation of HepG2 cells. Carlyle accumulated ultrasound microbubbles carrying HSV-TK on the surface of HepG2 cells and detected proliferating cell nuclear antigen (PCNA) and thiazolyl blue (MTT) [23, 24]. He found that the proliferation ability of targeted microbubbles was significantly decreased, and the apoptosis was significantly increased. The cell invasion test of Carlyle showed that the gene targeted microbubbles group $(22.18 \pm 2.01)$ was significantly less than that of the control group and the nontargeted microbubbles group, which had a good inhibitory effect on the proliferation and invasion of HepG2 cells [25]. Therefore, gene targeted microbubbles have a good inhibitory effect on HepG2 cells. Ultrasound targeted microbubble destruction (UTMD) is a noninvasive microRNA delivery method. Carlyle's research method is relatively advanced, but its practicability still needs to be further verified. Based on the analysis of the basic state and characteristics of albumin nanoparticles and ultrasound microbubble system, 11 dogs were selected and divided into two groups. In the experimental group, albumin nanoparticles ultrasound microbubble carrier was used to treat the thrombus after cardiac valve replacement preventive effect.

\section{Materials and Methods}

\subsection{Relevant Materials}

(1) Eleven healthy domestic dogs weighing $28-36 \mathrm{~kg}$ were male. They were divided into control group $(n=5)$ and treated with cardiac valve replacement and nonanticoagulant therapy. In the experimental group, 6 rats underwent cardiac valve replacement and targeted gene therapy.

(2) The reagents used included plasmid pSec Tag 2B, competent cells E. coli JM109, hamster ovary cells, dh5a competent bacteria, RNAiso Plus, PrimeScript,
RT Master Mix (perfect real time), SYBR Premix Ex $\mathrm{Taq}^{\mathrm{TM}}$ II (TLI RNaseH Plus). HindIII, KpnI, BamHI, and XhoI, and E.Z.N.A. Endo-Free Plasmid Maxi Kit. Human umbilical vein endothelial cell line EA.hy926 Cells. DMEM/F12 basic medium, dipalmitoylphosphatidylcholine (DSPC). Methods: Vent DNA polymerase and T4 DNA ligase, fetal serum, $0.25 \%$ Trypsin-EDTA, and Opti-MEM, respectively. Sheep anti-human tPA polyclonal antibody, rabbit anti-sheep polyclonal antibody, and AssayMax human tissue-type plasma activator ELISA kit. Bovine serum albumin (BSA), tPA ELISA kit, and halocarbon-218 were used.

(3) The related instruments include rotary evaporator, rotary evaporator, vacuum drying oven, one hundred thousandth electronic balance, ultrasonic cleaner, ultrasonic gene transfection system, laser particle size detection, and zeta potential analyzer, probe diameter $0.8 \mathrm{~cm}^{2}$, probe area, probe frequency $3 \mathrm{MHz}$, energy range $0-6 \mathrm{w} / \mathrm{cm}$, built-in working cycle pulse setting and digital timer, optical microscope, ultrasonic vibrometer, $\mathrm{CO}_{2}$ incubator, ultra clean table, precision $\mathrm{pH}$ meter, fluorescence microscope, desktop high-speed low-temperature centrifuge, circulating water vacuum pump, and multifunctional enzyme marker.

\section{Methods}

After operation, a thromboembolism model was established in dogs to replace heart valves and plasma activator gene (TPA) encapsulated in nanoparticles. Albumin nanoparticles were prepared and transported by albumin ultrasound microbubble channel. The effects of albumin nanoparticles on thrombosis and local vascular smooth muscle cell proliferation were observed. The plasmids with high expression of tPA gene were prepared, and plasma nanoparticles carrying tPA were prepared from albumin. Albumin was used to prepare glycosidic acid ultrasound microbubble channel and combined with tPA-loaded plasma nanoparticles to form targeted diagnostic ultrasound microbubble vector. After mechanical tricuspid valve replacement in dogs, targeted ultrasound diagnosis was performed to observe the preventive effect of postoperative thrombosis. The expression of tPA antigen in heart tissue was detected by immunohistochemistry, and the content of tPA and D-dimer in blood was detected by ELISA. At the end of the experiment, local thrombosis was observed in each group. It should be noted that the heart valve should be taken as the center, about $1 \mathrm{~cm}$ of coronary artery and vein bridge should be taken, and the heart valve tissue from the anterior wall of the heart should be taken for routine, immunohistochemistry, and in situ hybridization. Immunohistochemistry was used to detect the expression of tPA in myocardium. The first antibody was sheep anti-human tPA polyclonal antibody (dilution 1/100). The expression of proliferating cell nuclear antigen (PCNA) was detected by LSAB method. Anti-PCNA mouse monoclonal antibody (diluted 1/400) was performed according to the kit. Human 
lung cancer was positive for PCNA and PBS was used as negative control instead of antibody. A PDGF-B mRNA oligonucleotide detector was designed. The sequence was position 91 5-gat CGC ACC AAT GCC AAC ttcctg GTG TGG CCG CCC TGC GTG gag GTG cag-3141. The effectiveness and specificity of digoxin were detected by dot blot hybridization. The concentration of digoxin $(1.5 \mathrm{ng} / \mathrm{UL})$ was determined. The expression of PDGF-B mRNA was detected by conventional in situ hybridization. Then, the internal thickness and area of coronary artery were measured by pathological image analyzer, and the ratio of corneal thickness was calculated accurately. The formula was as follows: lumen stenosis rate $=(1-$ existing lumen area/area below the elastic membrane) $\times 100 \%$. The number of PCNA positive cells in 200 coronary artery cells was measured as the number of in situ hybridization positive cells. After statistical calculation, the internal area is $0.25 \mathrm{~cm}^{2}$ to $\times 4$ (i.e., $\left.1 \mathrm{~cm}^{2}\right)$, which is lower than the high-power field $(\times 400)$ of the microscope.

3.1. Construction and Expression of Gene Plasmid. In this experiment, three pairs of primers were designed according to three EST sequences and tPA gene sequences to amplify the three fragments of tPA from three EST cloning plasmids. Three EST clones were cultured on LB containing ampicillin and chloramphenicol. Three EST clone plasmids were extracted and three tPA amplified fragments were used as PCR vectors. The enhancement products were recovered and identified in sequence analysis. HindIII and XhoI, HindIII and KpnI, KpnI and BamHI, and BamHI and XhoI were digested by pSec Tag 2B and three tPA-tPA-1, tPA-2, and tPA-3, respectively. The products were cleaned with Qiagen PCR product purification kit. Meanwhile, T4 DNA ligase was used. The decontamination products were transformed into E. coli JM109 cells by $14^{\circ} \mathrm{C}$ overnight. The resistant colonies were screened from LB tablets containing ampicillin. The recombinant plasmids were detected by PCR, and the recombinant plasmids were extracted and identified. The recombinant plasmid was transfected into $\mathrm{CHO}$ cells by calcium phosphate coprecipitation method. The expression of tPA was detected by indirect immunofluorescence.

The primers for tPA gene and three EST sequences are as follows: t-PA-1F: 5'-CCCaagcttATGGATGCAATGAAGAGAGGG-3', t-PA-1R: 5'-GGggtaccACGGTAGGCTGACCCATTC-3', t-PA-2F: 5'-GGggtaccCACAGCCT CACCGAGTCG-3', t-PA-2R: $\quad 5^{\prime}$-CGggatccAGCAGGAGCTGATGAGTATGCC-3', t-PA-3F: $5^{\prime}$-CGggatccTCT CTGCCGCCCACTGCT' ${ }^{\prime} 3^{\prime}$, t-PA-3R: $5^{\prime}$-CCctcgagGCG GTCGCATGTTGTCAC- $3^{\prime}$.

The primer sequence of the primer sequence is t-PA-1F: $5^{\prime}$-CCC aag ctt ATG GAT GCA ATG AAG AGA GGG-3', tPA- 1R: $5^{\prime}$ - GGg gta ccA CGG TAG GCT GACCCA TTC3', t-PA-2F: 5' -GGg gta ccC ACA GCCTCA CCG AGT CG$3^{\prime}$, t- PA- 2R: 5'-CGg gat ccAGCA GGA GCT GAT GAG TAT GCC-3', t-PA-3F: $5^{\prime}$-CGg gat ccT CTC TGC CGC CCA CTG CT ${ }^{\prime}-3^{\prime}$, t-PA-3R: $5^{\prime}$-CCc tcg agG CGG TCG CAT GTT GTCAC-3'. The lowercase sequences were HindIII, KpnI, BamHI, and XhoI.
Three fragments were amplified and sequenced. The plasmid pSec Tag 2B and three fragments t-pa-t, PA-2, and t-pa-3 were digested and purified with hind 3 and xho3, hind 3 and kpn854444, kpn3 and bamh2, and bamh 3 and xho854444. T4dna lithium was extracted overnight under $14^{\circ} \mathrm{C}$ ligase. The ligation products were transformed into $E$. coli JM109 cells, and anti-ampicillin colonies were collected, and recombinant plasma was extracted and cultured for identification. The recombinant plasmid was transfected into plasma of Chinese hamster ovary cells by calcium phosphate coprecipitation method. The expression of tPA antigen was detected by immunofluorescence.

\subsection{Preparation of Ultrasound Microbubbles. First, a sterile} $10 \mathrm{ml}$ bovine serum albumin liquid $(5 \%(\mathrm{~g} / \mathrm{M})$ was prepared, in which $10 \%$ sucrose was prepared and placed in a $50 \mathrm{ml}$ covered plastic centrifuge tube. Oxygen and charcoal gas were used to corrode the liquid (flow rate: $6 \mathrm{ml} / \mathrm{min}$ ), about $10 \mathrm{~min}$, ultrasonic treatment was carried out for 1 minute in turn (condition: $180 \mathrm{~W}$, stable frequency: $20 \mathrm{kHz}$ ), and the prepared micropores were stored at $4^{\circ} \mathrm{C}$ for future use. The morphology, size, and number of microvessels were observed under microscope. The size and surface zeta potential of the microvessels were measured by Zetasizer 3000 analyzer.

Secondly, on the one hand, the albumin nanoparticles (containing $1 \mathrm{mg}$ plasmid) were added into $5 \mathrm{ml}$ albumin microbubbles and $10 \mathrm{ml}$ of $50 \%$ glutaraldehyde solution and then incubated at $4^{\circ} \mathrm{C}$ for 2 hours for interconnection (the final concentration of glutaraldehyde solution was $0.1 \%$ ). On the other hand, during the preparation of nanoparticles, the supernatant was collected after centrifugation, and the amount of plasmid remaining in the nanoparticles was detected. The encapsulation ratio shall be calculated according to the ratio of total amount to balance. The amount of plasmids carrying albumin nanoparticles ultrasound microbubble complex was calculated.

With normal serum, centrifugation, stratification, centrifugation speed of $200 \mathrm{r} / \mathrm{min}$, for 1 minute, suspension foam was obtained to obtain nano microbubbles containing targeted ultrasound contrast factor (carrier) gene $0.88 \times 10^{9} \sim 1.8 \times 10^{9} / \mathrm{ml}$ microbubbles were found in $10 \mathrm{ml}$ targeted contrast medium, and the gene plasmid content was $2 \mathrm{mg}$. It is then stored at 4 degrees Celsius for later use.

Finally, Zetasizer 3000 was fully used to determine the size and zeta potential of albumin nanoparticles. Albumin nanoparticles need gel retardation test and encapsulation efficiency test. The prepared albumin nanoparticles (containing $2 \mathrm{mg}$ plasmid) were added into $10 \mathrm{ml}$ albumin microbubbles, added $50 \%$ glutaraldehyde solution $10 \mathrm{ml}$, and incubated for $2 \mathrm{~h}$ at 4 degrees Celsius. After crosslinking, centrifugation (rotating speed $200 \mathrm{r} / \mathrm{min}, 1$ minute), suspension foam was obtained, and then the carrier was obtained. The microbubble concentration was adjusted to $(0.8-1.8) \times 10^{9}$ cells $/ \mathrm{ml}$.

\subsection{Targeted Ultrasound Therapy of TPA Gene-Loaded Al-} bumin Nanobubbles. The distribution of albumin nanoparticles in vivo mainly depends on its size and surface 
properties. Nanoparticles have a solid particle skeleton. Only nanoparticles with a diameter less than $100 \mathrm{~nm}$ can pass through the hepatic sinusoidal endothelial cell window and accumulate in the liver without entering the human body. Nanoparticles modified with hydrophilic groups in the range of 100-200 nm can avoid phagocytosis of reticuloendothelial system and become a long circulating system. To obtain colloidal system with good physical and chemical properties is a prerequisite for the use of protein nanoparticles as drug carriers and surfactants. Therefore, the preparation process has an important impact on the in vivo activity and targeting of albumin nanoparticles after intravenous injection. After tricuspid valve replacement in the experimental group, the heart rate of chest wall surface was detected by two-dimensional ultrasound. Imaging. After intravenous injection of $10 \mathrm{ml}$ albumin nanovesicles containing tPA gene, cardiac imaging was significantly improved. The chest wall was directly connected to the right ventricular tube of the anterior wall of the heart for 30 minutes. The chest wall was examined by two-dimensional ultrasound to observe the description of the heart. The ultrasonic frequency was $1 \mathrm{MHz}$ and the intensity was $1.5 \mathrm{w} / \mathrm{cm}^{2}$. In the control group, the tricuspid valves were replaced by conventional cardiopulmonary bypass $(\mathrm{CPB})$, and then they were intravenously injected with $10 \mathrm{ml}$ normal saline and irradiated with ultrasound (as before). Intravenous injection of tPA $10 \mathrm{ml}$ gene (containing tPA $2 \mathrm{mg}$ ) of nano albumin microvascular can significantly improve the development of related organs. Postoperative antibiotics were used to prevent traumatic infection. There was no anticoagulant therapy in each group. Before and after the operation (four weeks), the content of D-dimer and tPA were detected by ELISA. A dephosphorylase is used to remove the phosphorus group at the fifth end of DNA. Dephosphorylation of 5-limb vectors can reduce the occurrence of self-cyclization of vectors, thus reducing the production of false positive clones.

In order to improve the therapeutic potential of UTMD, microbubble gene vectors should have sufficient capacity to concentrate DNA and/or specific cell or tissue selectivity. Therefore, after 70-80\% digestion of EA.Y926 cells the day before the experiment, 5000 wells were divided into 96 vertical plates and cultured overnight at $70-80 \%$ fusion rate. Albumin nanoparticles with plasmid content of $0.05 \mathrm{UG}$, $0.1 \mathrm{mg}, 1 \mathrm{mg}$, and $10 \mathrm{UG}$ were added into each axis, which was composed of $0.5 \mathrm{UG} / \mathrm{ml}$ plasmid, $1 \mathrm{UG} / \mathrm{ml}, 10 \mathrm{UG} / \mathrm{ml}$, and $100 \mathrm{UG} / \mathrm{ml}$, and added into the conventional culture medium, and incubated at room temperature for 20 hours. Then, add 10 u1CCK- 8 solution to each well. The plates were incubated in incubator for 4 hours. The absorbance at $450 \mathrm{~nm}$ was determined by enzyme-linked immunosorbent assay, and the number of units was calculated according to the standard curve.

\section{Results and Discussion}

On the one hand, with the development of molecular biology, tissue-type plasminogen activator (tPA) has been used as a target for gene therapy in thrombosis-related diseases, so as to achieve the purpose of anticoagulation. This not only avoids the systemic bleeding complications caused by drug thrombolysis, but also plays a role in the local long term to prevent thrombosis. Intravenous tissue plasminogen activator (tPA) was first introduced as a safe and effective thrombolytic agent, and then new thrombolytic agents, anticoagulants, and antiplatelet drugs were introduced. These drugs were considered as potential safety drugs with more favorable interactions. In addition to chemical thrombolysis, other techniques, including transcranial ultrasound thrombolysis and microbubble cavitation, have been introduced.

4.1. Analysis of Albumin Nanoparticles and Microbubbles. The average diameter of nanoparticles is $132.0 \mathrm{~nm}$ and the average surface area of zeta is $+31.88 \sim+40.03 \mathrm{mv}$. The average entrapment efficiency was $73.97 \%$. Gel retardation analysis and DNase I protection experiments showed that nanoparticles had protective effect on DNA plasma. The ultrasonic microsphere was round and vesicular, with uniform size and good dispersion, and the diameter was $2-5 \mu \mathrm{m}$. The albumin microbubbles containing $10 \%$ sucrose were stored at $4^{\circ} \mathrm{C}$ for 30 days with the same morphology and good thermal stability $\left(40^{\circ} \mathrm{C}\right.$ for 30 minutes). After interaction with albumin nanoparticles, the above properties did not change significantly. The particle size and zeta potential are shown in Table 1.

Under the microscope, the cationic microbubble suspension was observed. The microbubbles were spherical in shape, and the size distribution was uneven. There was no obvious fusion and rupture. It is not difficult to see from Table 1 that the average size of microbubbles is $3.1 \pm 1.6 \mu \mathrm{m}$ and zeta potential is $13.70 \pm 1.95 \mathrm{MV}$. The microbubble concentration was $(4.2 \pm 1.3) \times 10 / \mathrm{ml}$. The particle size was $218.1 \pm 1.1 \mathrm{~nm}$ and zeta potential was $-15.30 \pm 0.91 \mathrm{MV}$. The average size of nanoparticles ultrasound microbubble complex was $4.5 \pm 1.8 \mu \mathrm{m}$. The zeta potential was $2.79 \pm 1.40 \mathrm{MV}$. The concentration was $(3.0 \pm 1.3) \times 10 / \mathrm{ml}$.

The results of particle size, morphology, and entrapment efficiency of tPA-loaded albumin nanoparticles are shown in Figure 1 .

According to Figure 1 and SEM results, albumin nanoparticles are spherical, uniform in size, and well dispersed. The particle size analysis of Zetasizer 3000 showed that the average particle size was $132.0 \mathrm{~nm}$, the maximum particle size was $153.1 \mathrm{~nm}$, and the minimum particle size was $48.9 \mathrm{~nm}$. The average multiple scattering index is 0.34 . The average surface area of zeta was $31.32 \pm 41.42 \mathrm{MV}$. The blocking rate of the sample was detected by UV spectrophotometer, and the total DNA content of plasmid was determined. The results showed that the average absorption efficiency was $73.58 \%$, which met the experimental requirements.

4.2. Survival Rate of Albumin Nanoparticle Ultrasound Microbubble Complex. In vitro and in vivo ultrasound imaging experiments show that complex of albumin nanoparticle microbubbles has a significant impact on ultrasound imaging, indicating that the microbubbles still 
TABle 1: Particle size and zeta potential.

\begin{tabular}{lcc}
\hline & Particle size & Zeta potential \\
\hline Plasmid albumin nanoparticles & $218.1 \pm 1.1 \mathrm{~nm}$ & $-15.30 \pm 0.91 \mathrm{mV}$ \\
Cationic microbubbles & $3.1 \pm 1.6 \mathrm{~nm}$ & $13.70 \pm 1.95 \mathrm{mV}$ \\
Albumin nanoparticles ultrasound microbubble complex & $4.5 \pm 1.8 \mathrm{~nm}$ & $2.7 \pm 1.40 \mathrm{mV}$ \\
\hline
\end{tabular}

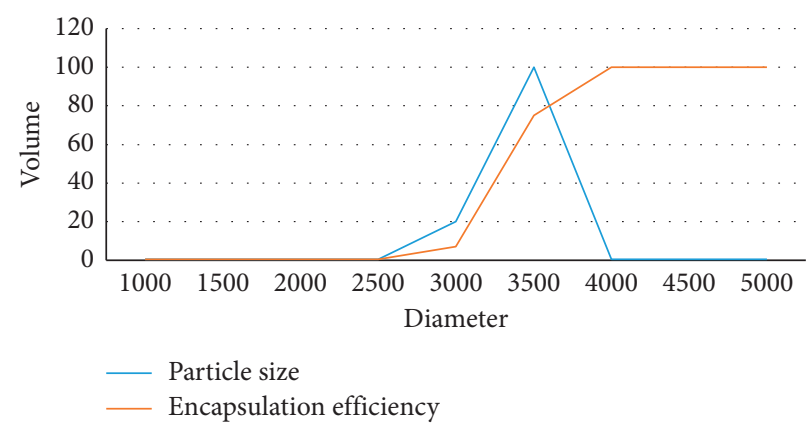

Figure 1: Analysis of particle size of Zetasizer 3000 instrument.

have good acoustic performance even after inhalation of nanoparticles. We treated the complex of albumin nanoparticle ultrasound microbubbles with endothelial cells EA.hy926. Albumin nanoparticles were detected in the acute toxic cells of ultrasound microbubble complex for 20 hours. The cell survival rate of albumin nanoparticles ultrasound microbubble complex is shown in Figure 2.

According to the data in Figure 2, for most concentration groups, there was no obvious cytotoxicity effect; only slight decrease of cell activity was observed in the highest concentration group, and the average cell activity was between $80 \%-120 \%$ compared with the control group.

\subsection{Comparison of tPA Content before and after Operation.} Thrombolysis or microthrombosis in situ may be the cause of poor clinical improvement after recanalization in acute ischemic stroke. Therefore, the thickness and area of heart valve are one of the important factors. The comparison of intimal thickness and area between the 5 normal dogs in the control group who underwent cardiac valve replacement and nonanticoagulant therapy alone and the 6 dogs in the control group receiving targeted gene transfer therapy at the same time with cardiac valve replacement is shown in Figure 3.

It can be seen from Figure 3 that the average thickness of the heart valve in the control group is $67.22 \mathrm{~nm}$, and the average thickness of the six ordinary dogs in the experimental group is $17.14 \mathrm{~nm}$. In the comparison of area size, the average thickness of the control group is $24.95 \mathrm{~mm}$, and the data of the experimental group is $21.13 \mathrm{~mm}$. The detection results of blood D-dimer and tPA before and 4 weeks after targeted gene transfer in experimental group and control group are shown in Table 2 .

It can be seen from Table 2 that the D-dimer and tPA content of the control group before operation were $78.36 \pm 6.12$ and $0.19 \pm 0.08$, respectively, and the two values after operation were $80.50 \pm 3.35$ and $0.18 \pm 0.03$, respectively. At the same time, the levels of D-dimer and tPA were $79.22 \pm 4.56,0.17 \pm 0.05,856.78 \pm 100.20$, and $0.67 \pm 0.11$ in the control group before and after the operation. The two indexes of fibrinolytic activity in the experimental group were significantly higher than those before the gene transfer, the control group before and after the operation. There was no significant difference in the ratio. The changes of tPA and $\mathrm{D}$-dimer in venous blood of experimental group at different periods after operation are shown in Figure 4.

It can be seen from Figure 4 that the average value of tPA in the experimental group before operation is 0.19 , and it changes to 0.50 one week after operation. At this time, $\mathrm{D}$-dimer also changes from 89.56 to 835.28 . In the following weeks, the content of tPA increased steadily until the eighth week, and then slightly decreased to 0.79 at the 12 th week after operation, but the tPA content was still very high, and the change trend of D-dimer was roughly the same as that of tPA. In the experimental group, the two indexes were significantly increased and maintained at a high level 1 week after operation until the end of the experimental observation at 12 weeks after operation. Prothrombin time was detected and the international normalized ratio was calculated, and no significant change was found. 


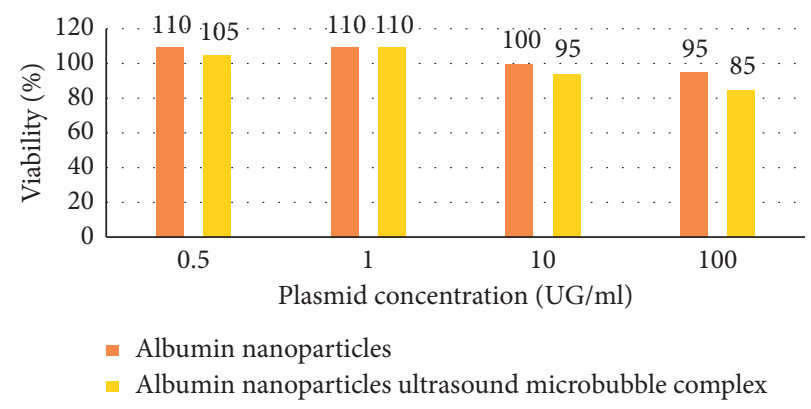

FIGURE 2: Cell viability of nanoparticles and nanoparticle ultrasound microbubble complexes.

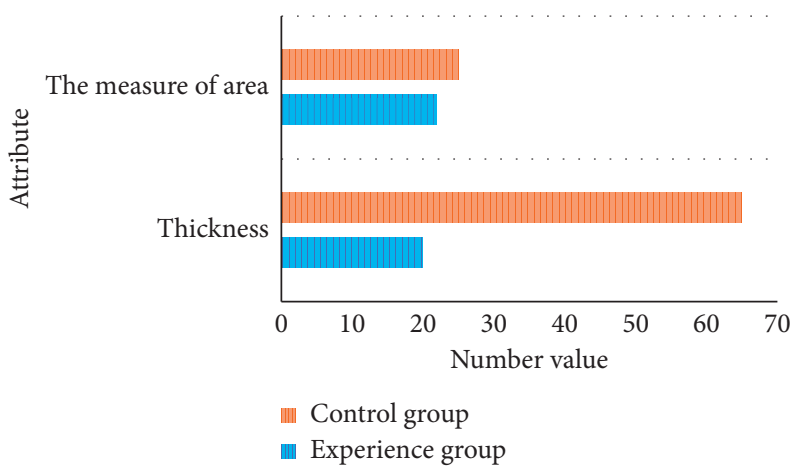

FIGURE 3: Results of cardiac valve morphology measurement in each group.

TABLE 2: D-dimer before and 4 weeks after targeted tPA gene transfer and tPA content $(\mu \mathrm{g} / \mathrm{L}, X \pm s)$.

\begin{tabular}{|c|c|c|c|}
\hline Grouping & & D-dimer & TPA content \\
\hline \multirow[b]{2}{*}{ Control group } & Preoperative & $78.36 \pm 6.12$ & $0.19 \pm 0.08$ \\
\hline & $\begin{array}{c}\text { After } \\
\text { operation }\end{array}$ & $80.50 \pm 3.35$ & $0.18 \pm 0.03$ \\
\hline \multirow{2}{*}{$\begin{array}{l}\text { Experience } \\
\text { group }\end{array}$} & Preoperative & $79.22 \pm 4.56$ & $0.17 \pm 0.05$ \\
\hline & $\begin{array}{c}\text { After } \\
\text { operation }\end{array}$ & $856.78 \pm 100.20$ & $0.67 \pm 0.11$ \\
\hline
\end{tabular}

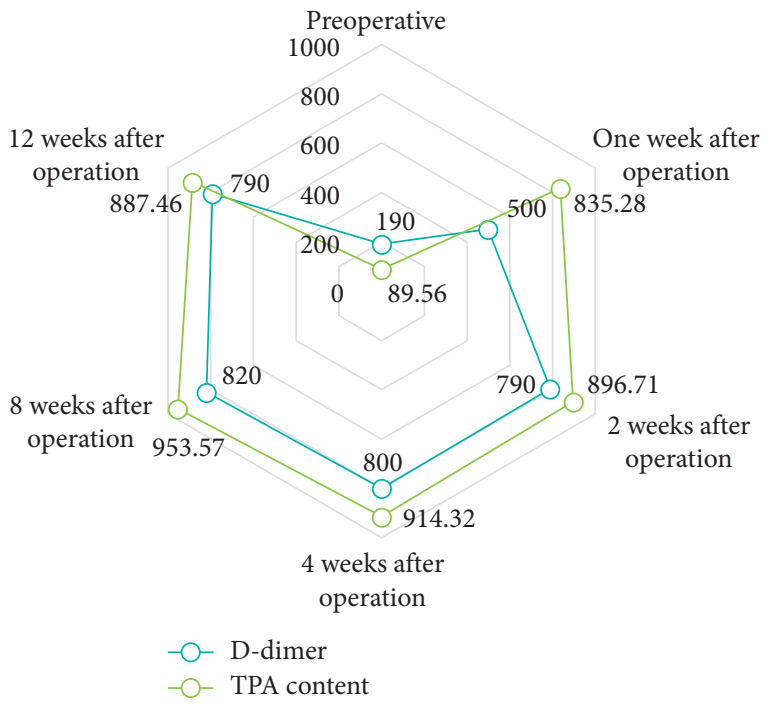

Figure 4: Changes of tPA and D-dimer in venous blood after valve replacement in control group $(x \pm s, \mu \mathrm{g} / \mathrm{ml})$.

\section{Conclusions}

Most methods of gene transfer into human body are to inject the target gene into target tissue directly. For cardiovascular diseases, direct injection of myocardial or plasmid DNA or adenovector into cardiac catheters is carried out. In view of the application of ultrasound contrast agent, microbubbles have been confirmed to have the function of directional delivery while enhancing ultrasound imaging by using microbubbles. It can target gene or drug delivery to achieve the purpose of treatment of diseases and can create a safe and effective drug ultrasound-mediated targeted delivery system. At present, there are many studies on albumin as liquid membrane microbubbles, which are nontoxic and easy to prepare. The disadvantage is its poor stability. In this experiment, $10 \%$ sucrose was selected as glycoprotein, which not only avoided the above conditions, but also had good microbubble stability. Because the inert gas fluorocarbon is the most commonly used gas in the preparation of ultrasound microbubbles, in this experiment, we used the physical inhalation (one-step method) to prepare albumin nanoparticles loaded with tPA gene. The particle size was about $132.0 \mathrm{~nm}$, the particle size was relatively uniform, the dispersion was good, and the entrapment efficiency was $73.58 \%$. Gel electrophoresis analysis showed that it had a good protective effect on DNA enzyme. The slight damage of ultrasound on microbubbles may be reversible damage and permeability of target cell membrane caused by ultrasound or mechanical factors, resulting in the rupture of microbubbles with diameter of $7 \mathrm{~mm}$ and the expansion of endothelial cell space. The target gene reaches tissue cells 
through the gap between microbubble rupture and endothelial cells. In this study, tPA gene expression plasmid was constructed, and the appropriate vector was selected to transfer tPA into the body cells to obtain effective and sustained tPA production, so as to achieve the purpose of long-term anticoagulation and prevention of thrombosis. Using three EST cloning plasmids as matrix, three tPA fragments were amplified and cloned into pSec Tag 2B plasmid to prepare recombinant pSec Tag $2 \mathrm{~B}$ tPA. In the experimental group, although the normal endothelial cells attached to the surface of the biological valve, the degree of valve leaf degeneration has been slowed down, but the incidence of valve thrombosis is still high due to the incomplete and partial shedding of endothelium and no anticoagulant treatment after operation. The results showed that the targeted release and gene expression of albumin nanoparticles loaded with gene plasmids could be enhanced by ultrasound destruction of microbubbles. This method is a simple and effective new technology for targeted gene transfer. With the development of molecular biology and ultrasound medicine technology, it will provide a new way to study the prevention of human diseases.

\section{Data Availability}

The data used to support the findings of this study are included within the article.

\section{Disclosure}

Feng Qi and Linlin Zhao are considered as the co-first authors.

\section{Conflicts of Interest}

The authors declare no conflicts of interest regarding the publication of this paper.

\section{Authors' Contributions}

Feng Qi and Linlin Zhao contributed equally to this work.

\section{References}

[1] S. C. Hofferberth, M. Y. Saeed, L. Tomholt et al., "A geometrically adaptable heart valve replacement," Science Translational Medicine, vol. 12, no. 531, 2020.

[2] J. Jose, D. S. Sulimov, M. El-Mawardy et al., "Clinical bioprosthetic heart valve thrombosis after transcatheter aortic valve replacement," JACC: Cardiovascular Interventions, vol. 10, no. 7, pp. 686-697, 2017.

[3] D. Wojciechowska, A. R. Liberski, P. Wilczek et al., "The optimal shape of an aortic heart valve replacement-on the road to the consensus," Qscience Connect, vol. 2017, no. 3, p. 1, 2017.

[4] H. Togun, M. Ahmed, L. Rabee, and F. Adel, "Evaluation study of heart valve replacement for patients aged from 10 to 80 years at Al-nasiriyah heart center/Iraq," Journal of Engineering and Applied Sciences, vol. 14, no. 4, pp. 1339-1348, 2019.
[5] O. Seddon, R. Ashrafi, J. Duggan et al., "Seroprevalence of Q fever in patients undergoing heart valve replacement surgery," The Journal of Heart Valve Disease, vol. 25, no. 3, pp. 375-379, 2016.

[6] A. Araújo-Filho, M. Cerqueira-Neto, L. Cacau, G. Oliveira, T. Cerqueira, and V. Santana-Filho, "Effect of prophylactic non-invasive mechanical ventilation on functional capacity after heart valve replacement: a clinical trial," Clinics, vol. 72, no. 10, pp. 618-623, 2017.

[7] D.-J. Kim, H.-S. Kim, M. K. Oh, E.-Y. Kim, and J.-G. Shin, "Cost-effectiveness of genotype-guided warfarin dosing in the patients with mechanical heart valve replacement under feefor-service system," Clinical Therapeutics, vol. 39, no. 8, p. e9, 2017.

[8] E. T. Mehmet and D. Mehmet, "The effectiveness of heart valve replacement surgery in a non-referral regional hospital: the analysis of outcomes after isolated and complex valve replacement," The Heart Surgery Forum, vol. 22, no. 5, pp. E343-E351, 2019.

[9] S. Oschatz, S. Kohse, V. Senz, T. Eickner, K.-P. Schmitz, and N. Grabow, "Accelerated in vitro-calcification of potential urethane based heart valve replacement materials," Current Directions in Biomedical Engineering, vol. 4, no. 1, pp. 221224, 2018.

[10] S. Ghazanfari, A. Driessen-Mol, S. P. Hoerstrup, F. P. T. Baaijens, and C. V. C. Bouten, "Collagen matrix remodeling in stented pulmonary arteries after transapical heart valve replacement," Cells Tissues Organs, vol. 201, no. 3, p. 159, 2016.

[11] X. L. Yang, D. Wang, G. Y. Zhang et al., "Comparison of the myocardial protective effect of sevoflurane versus propofol in patients undergoing heart valve replacement surgery with cardiopulmonary bypass," BMC Anesthesiology, vol. 17, no. 1, p. 37, 2017.

[12] Y. Lu, J. Wang, R. Huang et al., "Microbubble-mediated sonothrombolysis improves outcome after thrombotic microembolism-induced acute ischemic stroke," Stroke, vol. 47, no. 5, pp. 1344-1353, 2016.

[13] N. Ding, "Sleep apnea increase the perioperative risks of heart valve replacement surgery," Chest, vol. 149, no. 4, p. A575, 2016.

[14] L. P. Dasi, J. Grande-Allen, K. Kunzelman, and E. Kuhl, "The pursuit of engineering the ideal heart valve replacement or repair: a special issue of the annals of biomedical engineering," Annals of Biomedical Engineering, vol. 45, no. 2, pp. 307-309, 2017.

[15] W. Xiaowei, G. Yannik, P. Jathushan et al., "Thrombus-targeted theranostic microbubbles: a new technology towards concurrent rapid ultrasound diagnosis and bleeding-free fibrinolytic treatment of thrombosis," Theranostics, vol. 6, no. 5, pp. 726-738, 2016

[16] B. Mead, N. Kim, K. Negron et al., "Intersections of neuromodulation, focused ultrasound, and gene delivery with brain-penetrating nanoparticles," The Journal of the Acoustical Society of America, vol. 142, no. 4, p. 2669, 2017.

[17] J. A. Kopechek, A. R. Carson, C. F. Mctiernan et al., "Cardiac gene expression knockdown using small inhibitory RNAloaded microbubbles and ultrasound," PLoS One, vol. 11, no. 7, Article ID e0159751, 2016.

[18] A. Goyal, F. Yu, M. G. Tenwalde, X. Chen, F. Villanueva, and J. Pacella, "Low dose TPA improves reperfusion efficacy of microvascular obstruction using ultrasound with microbubbles," Journal of the American College of Cardiology, vol. 67, no. 13, p. 160, 2016. 
[19] H. Asadi, D. Williams, and J. Thornton, "Changing management of acute ischaemic stroke: the new treatments and emerging role of endovascular therapy," Current Treatment Options in Neurology, vol. 18, no. 5, pp. 1-19, 2016.

[20] L. Carlyle, D. D. Wang, A. Taylor et al., "NO two systoles the same: personalizing transcatheter heart valve selection for transcatheter aortic valve replacement," Journal of the American College of Cardiology, vol. 67, no. 13, p. 327, 2016.

[21] Y. Ji, Z. Han, L. Shao, and Y. Zhao, "Evaluation of in vivo antitumor effects of low-frequency ultrasound-mediated miRNA-133a microbubble delivery in breast cancer," Cancer Medicine, vol. 5, no. 9, pp. 2534-2543, 2016.

[22] W. Gao, L. Qiao, Y. Gao et al., "Effect of microbubble-enhanced ultrasound on percutaneous ethanol ablation of rat walker-256 tumour," European Radiology, vol. 26, no. 9, pp. 3017-3025, 2016.

[23] J. Wang, P. Li, R. Tian et al., "A novel microbubble capable of ultrasound-triggered release of drug-loaded nanoparticles," Journal of Biomedical Nanotechnology, vol. 12, no. 3, pp. 516-524, 2016.

[24] Y. Wang, X. Li, L. Liu, B. Liu, F. Wang, and C. Chen, "Tissue targeting and ultrasound-targeted microbubble destruction delivery of plasmid DNA and transfection in vitro," Cellular and Molecular Bioengineering, vol. 13, no. 1, pp. 99-112, 2020.

[25] B. Chertok, R. Langer, and D. G. Anderson, "Spatial control of gene expression by nanocarriers using heparin masking and ultrasound-targeted microbubble destruction," ACS Nano, vol. 10, no. 8, p. 7267, 2016. 